\title{
Cusp Prolapse Indicator
}

National Cancer Institute

\section{Source}

National Cancer Institute. Cusp Prolapse Indicator. NCI Thesaurus. Code C127553.

An indication as to whether there is a prolapsed cardiac valve cusp. 